\title{
KINETIC STUDY OF ADSORPTION OF HEXAVALENT CHROMIUM IN AQUEOUS SOLUTION USING BAY LEAF (LAURUS NOBILIS) AS NEW BIO-ADSORBENT
}

\author{
Suhad A. Yasin ${ }^{\mathrm{a}, *}$ and Amin K. Qasim ${ }^{\mathrm{a}}$
}

${ }^{\text {a }}$ Dept. of Chemistry, Faculty of Science, University of Zakho, Kurdistan Region - Iraq (Suhad.yasin@uoz.edu.krd)

\begin{abstract}
:
Laurus nobilis (Bay leaf), was examined for its capacity to remove hexavalent chromium $\mathrm{Cr}(\mathrm{VI})$ poisonous, from aqueous solution. The bio-adsorbent using bay leaf obtained from Laurus nobilis was investigated in batch experiments. The influence of main parameters such as chromium concentration, $\mathrm{pH}$ and shaking time are tests. The effect of beginning concentration of $\mathrm{Cr}(\mathrm{VI})$ ion ( 10 to $50 \mathrm{mg} / \mathrm{dm}$ ), $\mathrm{pH}$ (1 to 6 ) and shaking time ( 5 to $180 \mathrm{~min}$ ) have been reported. The optimum $\mathrm{pH}$ was found to be $\mathrm{pH} 4 . . \mathrm{Results}$ show that the most appropriate model was pseudo second-order kinetic and it correlate with the trial statistics well.
\end{abstract}

KEYWORDS: Laurus nobilis; Hexavalent Chromium; Adsorption kinetics; Waste water.

\section{INTRODUCTION}

The heavy metal is an essential environmental issue because of poisonous influence and collecting during the food chain. The most dangerous heavy metal pollutants such as $\mathrm{Cr}, \mathrm{Pb}, \mathrm{Hg}, \mathrm{cd}$, Ni. Because of contaminants' carcinogenic and mutagenic nature[1]. Discharge effluent containing hexavalent chromium $\mathrm{Cr}(\mathrm{VI})$ from different source of industrial are hosted into natural waters like stainless steel production, corrosion control, paint and pigment manufacturing textile, leather tanning[2]. Chromium ion $\mathrm{Cr}(\mathrm{VI})$ is most dangerous than $\mathrm{Cr}(\mathrm{III})$ and the percentage level of $\mathrm{Cr}$ (III) and $\mathrm{Cr}$ (VI) ions in aqueous solution are 5 and $0.05 \mathrm{mg} / \mathrm{dm}$, respectively. While $\mathrm{Cr}(\mathrm{VI})$ apparently plays an vital part in animal and plant metabolism[3].

There are different methods utilized for remove heavy metal ions from aqueous solution such as chemical precipitation, lime coagulation, reverse osmosis and adsorption[4]. The disadvantages of these methods are long time, complicated and economic expensive because of using expensive reagent and energy requirements.

The main aim for this study is investigate the removal of hexavalent chromium and other heavy metal later on using some of local of tree leaves. However, it should be economic inexpensive and environmental friendly. Plants and the tree leaves such as bay leaf have been demonstrated for its activity for cleaning of air pollution in general and equilibrium environment. However, there are few researches have been conducted previously to utilize the tree leaves as aqueous solution cleaner. In the present work Bay leaf (Laurus Nobilis), has been proven for its ability to remove the $\mathrm{Cr}(\mathrm{VI})$ from aqueous solution.

\section{MATERIALS AND METHODS}

\subsection{Metal solution}

A $\mathrm{Cr}$ (VI) standard solution of $500 \mathrm{mg} / \mathrm{dm}$ was prepared by dissolving 1.414g of $\mathrm{K}_{2} \mathrm{Cr}_{2} \mathrm{O}_{7}$ (sigma Aldrich) in 1L of DIW, this standard was utilized for all other preparations. Analytical grade reagents were used throughout this study.

\subsection{Preparation of adsorbent}

Bay leaves (Laurus Nobilis) were randomly collected from local Duhok market( from gara mountain). The bay leaves were pulverized and sieved (500 micrometer) to obtain particles of uniform sizes.

\subsection{Chemical analysis}

Atomic absorption spectroscopy (AAS) was utilized to estimate the concentrations of metal ion in wastewater (AAnalyst200_Perkin Elmer). For the excellence control purpose, deionized water digested and analyzed with every sample group to track any possible contamination source.

A triplicate analyzed for every sample and the standard deviation of the reading is $( \pm 1 \%$.).

\subsection{Adsorption Study}

Adsorption isotherm experiments were carried out at adsorbent dose $(1 \mathrm{~g} / \mathrm{dm})$ and different $\mathrm{Cr}(\mathrm{VI})$ concentrations $(10,20,30$, 40 and $50 \mathrm{mg} / \mathrm{L}$ ). At each adsorbent dose, each solution was shacked for 120 minutes at $\mathrm{pH} 4$ and at room temperature. The amount percentage of chromium adsorbed onto adsorbent (g), was calculated using the following equation:

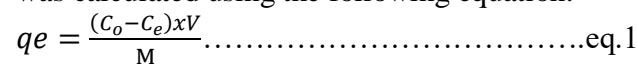

Where $C_{0}$ is initial concentration (ppm) and $C_{e}$ is equilibrium of $\mathrm{Cr}(\mathrm{VI})$, respectively, $V$ is the volume(L), $M$ is the weight of the adsorbent used $(\mathrm{g})$.

The Cr(VI) percent removal $R \%$ (adsorption efficiency) was calculated using the following equation:

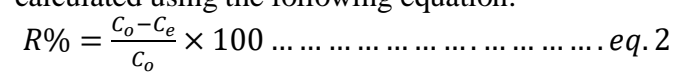

\section{RESULT AND DISCUSSION}

The result indicated that the It was appear that the extreme abstraction of chromium from aqueous solution using ( $1 \mathrm{~g} / \mathrm{dm})$ Bay leaf powder as adsorbent happened at $\mathrm{pH} \mathrm{4}$, and the time order for equilibrium was $80 \mathrm{~min}$ and the temperature was

\footnotetext{
* Corresponding author

This is an open access under a CC BY-NC-SA 4.0 license (https://creativecommons.org/licenses/by-nc-sa/4.0/)
} 
$25^{\circ} \mathrm{C}$. So all batch sorption experiments were done in these conditions.
The $\mathrm{pH}$ of the aqueous solution is a significant parameter for the removal of metal ions by adsorption .

\subsection{Influence of pH on chromium adsorption}

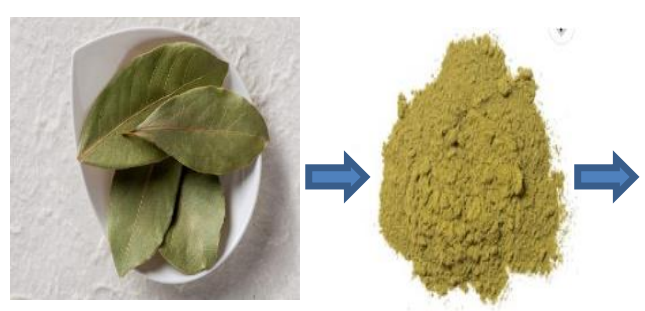

Bav leaves (Laurus nobiBdv leaves

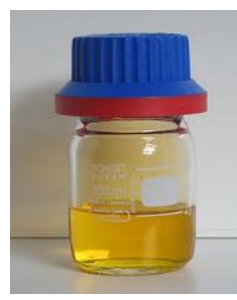

\section{Cr(VI)}

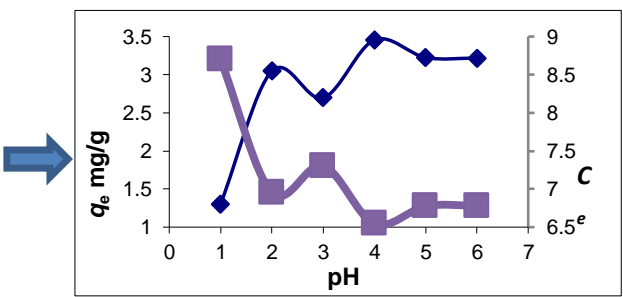

Scheme 1. Schematic illustration for the removal of $\mathrm{Cr}(\mathrm{VI})$ from synthetic solution using natural adsorbents.

In the this work, adsorption of $\mathrm{Cr}(\mathrm{VI})$ is considered in the original $\mathrm{pH}$ range of (1-6). As shown in the Figure(1) that the lowest adsorption happened at $\mathrm{pH} \mathrm{1,} \mathrm{a} \mathrm{decline} \mathrm{in} \mathrm{uptake} \mathrm{was,}$ in agreement with previous observations $[5,6]$ and the greatest sorption occurred at $\mathrm{pH} 4$. Removal efficiency increased from $5.8 \%$ to $98 \%$ with the $\mathrm{pH}$ range 1 to 4 respectively.

Chromium (VI) is present in waste water at different phase for example chromate $\left(\mathrm{CrO}_{4}{ }^{2-}\right),\left(\mathrm{H}_{2} \mathrm{CrO}_{4}\right)$. It is well known that the $\mathrm{pH}$ is effected to the form of the $\mathrm{Cr}(\mathrm{VI})$ for example at $\mathrm{pH}<7$ is $\mathrm{H}_{2} \mathrm{CrO}_{4}$ and at $\mathrm{pH}>7$ other forms $\left(\mathrm{CrO}_{2}{ }^{4-}\right.$ and $\left.\mathrm{Cr}_{2} \mathrm{O}^{2-} 7\right)$. It can be concluded that the $\mathrm{HCrO}_{4}^{-1}$ complex ion is not active form of $\mathrm{Cr}(\mathrm{VI})$ absorbed via bay leaf in this study.

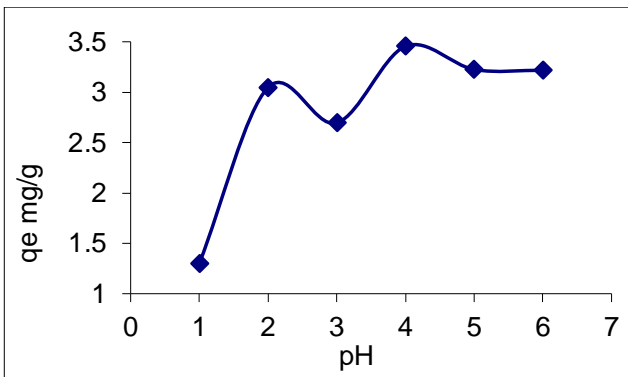

Figure 1. Influence of $\mathrm{pH}$ on the adsorption of $\mathrm{Cr}(\mathrm{VI})$ onto adsorbent,

\subsection{Influence of shaking time on $\mathrm{Cr}$ (VI) adsorption.}

The influence of time for removal of $\mathrm{Cr}$ (VI) by Bay leaf with a dose of $1 \mathrm{~g} / \mathrm{L}$ concentration is shown in Figure (2).There was a rapid adsorption happen when the time reaches to 40 to 80 minutes, then start to decrease and stabilized. The percent removal was $52.56 \%$ in the first 40 minutes and maximum removal was $70.41 \%$ in 80 minutes. This may be attributed to saturation of adsorbent surfaces with $\mathrm{Cr}$ (VI) followed by adsorption and desorption processes that occur after saturation.

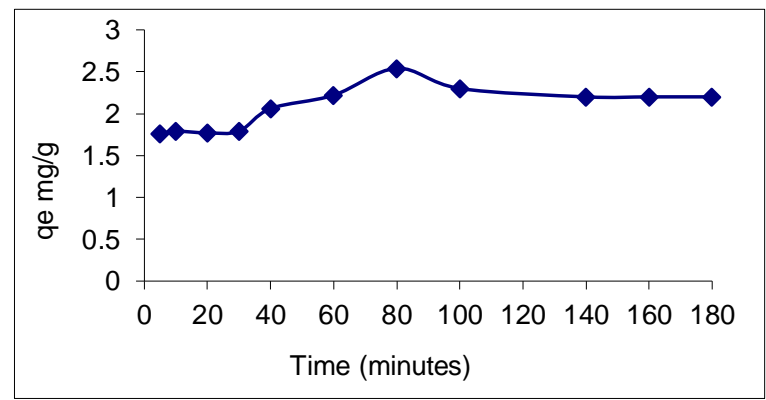

Figure 2. Influence of shaking time on the $\mathrm{Cr}(\mathrm{VI})$ onto adsorbent.

\subsection{Influence of original $\mathrm{Cr}(\mathrm{VI})$ ion concentration}

The influence of initial $\mathrm{Cr}(\mathrm{VI})$ ion concentration is studied via using $(10,20,30,40$ and $50 \mathrm{mg} / \mathrm{L})$ of chromium and dose of $1 \mathrm{~g} / \mathrm{L}$ Bay leaf. The adsorption capacity $q_{e}$ was plot against the concentration of $\mathrm{Cr}$ (VI). The relation is revealed for different initial concentration in Figure (3). It revealed that, $q_{e}$ increases with increase of concentration of $\mathrm{Cr}$ (VI) [7].

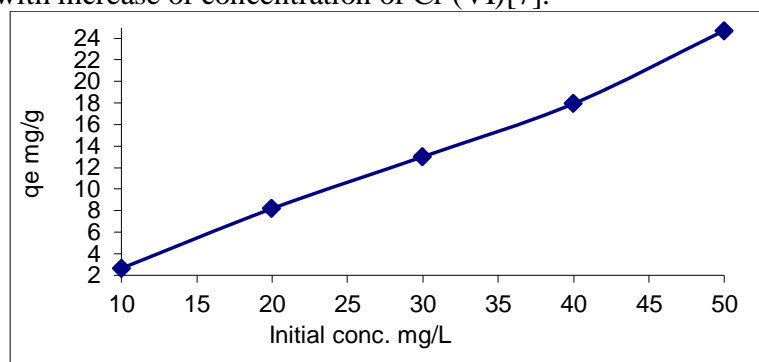

Figure 3. Relation between qe, and initial concentration

\subsection{Adsorption kinetic}

There are several type of kinetic model are utilized to estimate the amount of ions adsorbed to bay leaf. pseudo first order equation was utilized by Ho and Mckay [8].

$\log \left(q_{e}-q_{1}\right) \log q_{e}-\left(\frac{K_{1}}{2.303}\right) \ldots \ldots \ldots \ldots \ldots \ldots . . . . . . . . .3$

Where $q_{e}$ is adsorption capacities of $\mathrm{Cr}$ adsorbed $\left(\mathrm{mg} \mathrm{g}^{-1}\right)$ at equilibrium and $q_{t}$ at any time $t$, and $k_{l}$ is the equilibrium rate constant of pseudo-first order adsorption $\left(\mathrm{min}^{-1}\right)$.

The correlation coefficient of plot of $\log \left(q_{e^{-}} q_{t}\right)$ vs. $t$, indicated that, the first-order kinetic model do not describe the kinetic data of $\mathrm{Cr}$ (VI) adsorption. The true value of $q_{e}$. gained from trials is $2.76 \mathrm{mg} / \mathrm{g}$. after comparison between the true value of $q_{e}$ and pseudo first-order kinetics the result shown that firstorder kinetics are inadequate to give a good account of the kinetics of $\mathrm{Cr}(\mathrm{VI})$ adsorption on bay leaves.

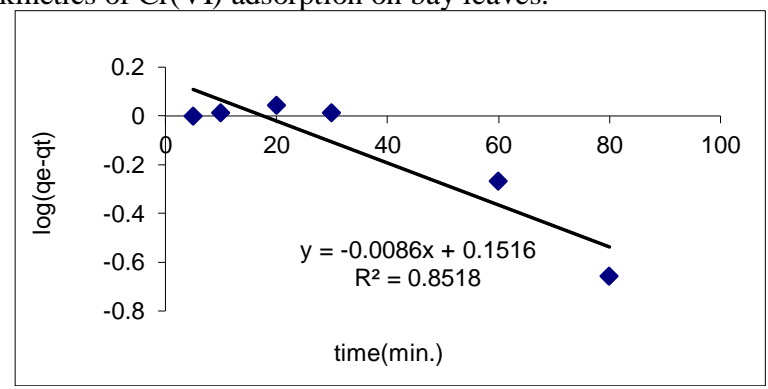

Figure 4. pseudo first - order kinetic for the adsorption

In such cases, the second order kinetics is most reasonable for estimate with the rate equation.

The Pseudo second-order equation [8] is expressed in a linear form as follows: 
$\frac{t}{q}=\frac{1}{k_{2} q_{e}^{2}}+\frac{1}{q_{e}}(t)$

Where, $\mathrm{k}_{2}\left(\mathrm{~g} \mathrm{mg}^{-1} \mathrm{~min}^{-1}\right)$ is the equilibrium rate constant. The initial adsorption rate, $h\left(\mathrm{mg} \mathrm{g}^{-1} \mathrm{~min}^{-1}\right)$ is uttered via the following equation.

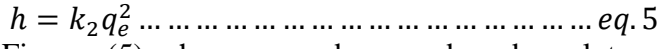

Figure (5) shows pseudo-second order plot, where the correlation coefficient is (0.9687). This high correlation coefficient suggests the $\mathrm{Cr}(\mathrm{VI})$ sorption is ruled by pseudosecond order.

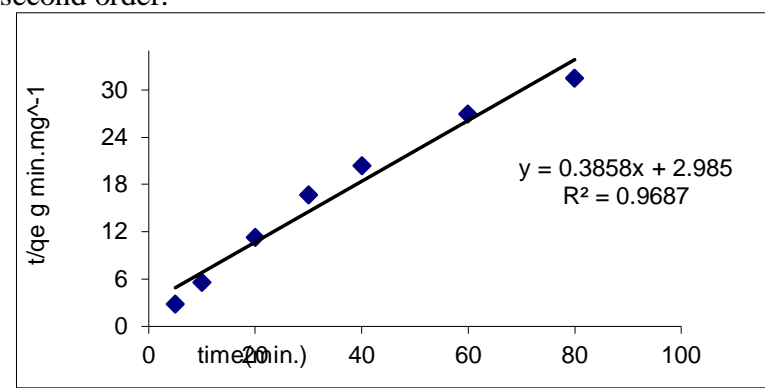

Figure 5. pseudo second order kinetic for the adsorption

Elovich model as modified by Chien and Clayton, which can be presented as in the linear form of Elovich equation is [9] $q_{t}=\frac{1}{\beta} \ln (\alpha \beta)+\frac{1}{\beta} \ln (t)$

...eq. 6

Where, $\alpha$ is the first adsorption rate and $\beta$ is the desorption constant. Plot of $q_{t}$ versus. $\ln (t)$ yield a linear relationship as shown in Figure(6).

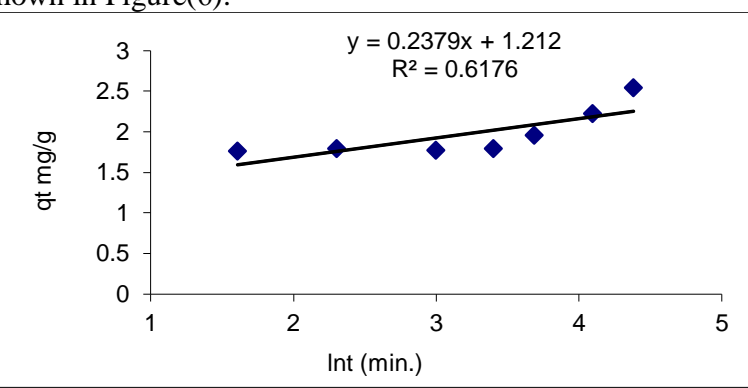

Figure 6. Elovich kinetic for the adsorption of $\mathrm{Cr}(\mathrm{VI})$ onto adsorbent.

Weber and Morris [10] derived the $q_{t}$ and the square root of time, $t^{1 / 2}$ as a rate of diffusion, as shown in equation (7): $q_{t}=K_{\text {dif }} t^{\frac{1}{2}}+B_{L}$ eq. 7

$B_{L}$ is the thickness of the boundary, and $K_{d i f}\left(\mathrm{mg} \mathrm{g}^{-1} \mathrm{~min}^{-1 / 2}\right)$ is the intraparticle diffusion rate constant. The slope and intercept of $q_{t}$ vs. $t^{1 / 2}$ plots are utilized to calculat $K_{d i f}$ and $B_{L}$ values respectively. The values of $K_{d i f}$ and $B_{L}$ are mentioned in Table 1 . If the plot of Figure (7) $q_{t}$ vs. $t^{1 / 2}$ gave a linear relationship [11].

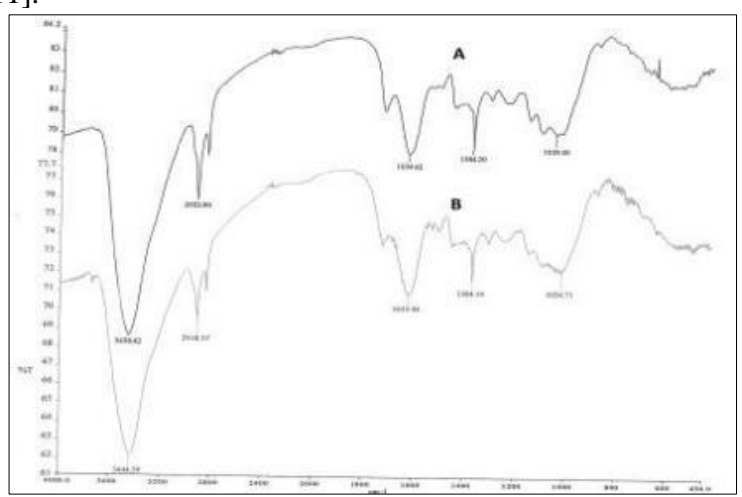

Figure 7. FTIR spectrum of Bay leaf (Laurus nobilis) A) before adsorption B)after adsorption of $\mathrm{Cr}(\mathrm{VI})$

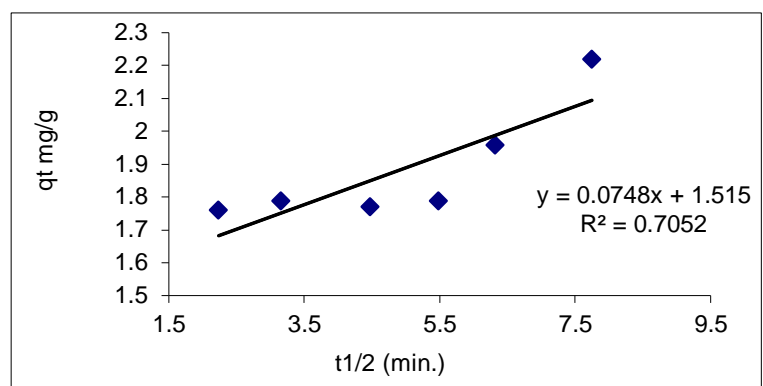

Figure 8. Intraparticle diffusion adsorption of of $\mathrm{Cr}$ (VI) onto adsorbent.

\subsection{E.FTIR Spectroscopy}

The intraction between the target $\mathrm{Cr}(\mathrm{VI})$ ion and absorbent was investigated via FT-IR, since the intensity may be reduced due to adsorption onto the surface of the adsorbent. Figure (8) demonstrations the IR spectra before and after adsorption of $\mathrm{Cr}(\mathrm{VI})$ onto Bay leaf. It is evident that some bands in the region have changed shapes which indicates that $\mathrm{Cr}(\mathrm{VI})$ ions have been adsorbed onto Bay leaf. The functional groups that are responsible of adsorption of metal ions are hydroxyle,carboxyl,carbonyl,amine,amide, amine,sulfonate and imidazole[11].

Table 1. Parameter and the value of this study at constant temperature $25 \mathrm{C}^{\circ}$ and different time intervals .

\begin{tabular}{|c|c|c|}
\hline kinetic model & parameters & Value \\
\hline \multirow{4}{*}{$\begin{array}{l}\text { Pseudo-first -order } \\
\text { kinetic model }\end{array}$} & $q \exp (\mathrm{mg} / \mathrm{g})$ & 2.76 \\
\hline & $k_{1}\left(\min ^{-1}\right)$ & 0.019805 \\
\hline & $q_{e}$ calc. $(\mathrm{mg} / \mathrm{g})$ & 1.16311 \\
\hline & $\mathrm{R}^{2}$ & 0.8518 \\
\hline \multirow{5}{*}{$\begin{array}{l}\text { Pseudo Second- } \\
\text { order kinetic model }\end{array}$} & $K_{2}\left(\mathrm{gmg}^{-1} \mathrm{~min}^{-1}\right)$ & 0.0496566 \\
\hline & $h\left(\mathrm{mg} \mathrm{g}^{-1} \min ^{-1}\right)$ & 0.3350 \\
\hline & $q_{e}$ calc. $(\mathrm{mg} / \mathrm{g})$ & 2.59743 \\
\hline & $\mathrm{R}^{2}$ & 0.9687 \\
\hline & $\beta\left(\mathrm{mgg}^{-1} \mathrm{~min}^{-1}\right)$ & 2.6385 \\
\hline \multirow{2}{*}{ Elovich model } & $\alpha\left(\mathrm{mgg}^{-1} \min ^{-1}\right)$ & 9.2776 \\
\hline & $\mathrm{R}^{2}$ & 0.6176 \\
\hline \multirow{3}{*}{$\begin{array}{r}\text { Intraparticle } \\
\text { diffusion }\end{array}$} & $\mathrm{K}_{\text {diff }}\left(\mathrm{mgg}^{-1} \mathrm{~min}^{-1 / 2}\right)$ & 0.0748 \\
\hline & $B_{L}(\mathrm{mg} / \mathrm{g})$ & 1.515 \\
\hline & $\mathrm{R}^{2}$ & 0.7952 \\
\hline
\end{tabular}

\section{CONCLUSIONS}

An environmental and low cost bio adsorbent is obtainable by bay leaves. The indigenous Bay leaf (Laurus Nobilis) has been recognized as an real adsorbent to remove the poisonous $\mathrm{Cr}(\mathrm{VI})$ ions from several kinds of its water samples. However, bio sorption observations that the ability of bay leaf to absorb the high amount of $\mathrm{Cr}(\mathrm{VI})$ concentration from waste waters. The optimal $\mathrm{pH}$ of the solution is 4 and it is the best $\mathrm{pH}$ for absorption of $\mathrm{Cr}(\mathrm{VI})$. The first-order, second-order kinetic, Elovich and intraparticle diffusion models have been used for the study of adsorption kinetics. Furthermore, the equilibrium data of adsorption are in matched with the second adsorption. The proposed adsorbent is efficient, environmentally approachable and can diminish the large amount of discharge ion everywhere the small industry worries.

\section{REFERENCE}

1. Pellerin, C. and S.M. Booker, Reflections on hexavalent chromium: health hazards of an industrial heavyweight. Environmental health perspectives, 2000. 108(9): p. A402. 
2. Saha, R., R. Nandi, and B. Saha, Sources and toxicity of hexavalent chromium. Journal of Coordination Chemistry, 2011. 64(10): p. 1782-1806.

3. Farinella, N., G. Matos, and M. Arruda, Grape bagasse as a potential biosorbent of metals in effluent treatments. Bioresource technology, 2007. 98(10): p. 1940-1946.

4. Dakiky, M., et al., Selective adsorption of chromium (VI) in industrial wastewater using low-cost abundantly available adsorbents. Advances in environmental research, 2002. 6(4): p. 533-540.

5. Yang, L. and J.P. Chen, Biosorption of hexavalent chromium onto raw and chemically modified Sargassum sp. Bioresource technology, 2008. 99(2): p. 297-307.

6. Dayan, A. and A. Paine, Mechanisms of chromium toxicity, carcinogenicity and allergenicity: review of the literature from 1985 to 2000. Human \& experimental toxicology, 2001. 20(9): p. 439-451.
7. Ho, Y., et al., Study of the sorption of divalent metal ions on to peat. Adsorption Science \& Technology, 2000. 18(7): p. 639-650.

8. Elovich, S.Y. and O. Larionov, Theory of adsorption from nonelectrolyte solutions on solid adsorbents. Russian Chemical Bulletin, 1962. 11(2): p. 198-203.

9. Weber, W.J. and J.C. Morris, Kinetics of adsorption on carbon from solution. Journal of the Sanitary Engineering Division, 1963. 89(2): p. 31-60.

10. Crini, G., et al., Removal of CI Basic Green 4 (Malachite Green) from aqueous solutions by adsorption using cyclodextrin-based adsorbent: Kinetic and equilibrium studies. Separation and Purification Technology, 2007. 53(1): p. 97-110.

11. Pradhan, S., S. Singh, and L.C. Rai, Characterization of various functional groups present in the capsule of Microcystis and study of their role in biosorption of $\mathrm{Fe}$, Ni and Cr. Bioresource technology, 2007. 98(3): p. 595-601. 